\title{
Determinants of virological failure among patients on highly active antiretroviral therapy in University of Gondar Referral Hospital, Northwest Ethiopia: a case-control study
}

\author{
This article was published in the following Dove Press journal: \\ HIVIAIDS - Research and Palliative Care \\ 8 August 2017 \\ Number of times this article has been viewed
}

\author{
Belete Bayu' \\ Amare Tariku² \\ Abera Balcha Bulti ${ }^{3}$ \\ Yohannes Ayanaw Habitu ${ }^{4}$ \\ Terefe Derso \\ Destaw Fetene Teshome ${ }^{5}$ \\ 'Wag Himra Zonal Health \\ Department, Sekota, ${ }^{2}$ Department \\ of Human Nutrition, Institute of \\ Public Health, ${ }^{3}$ Department of \\ Internal Medicine, School of Medicine, \\ ${ }^{4}$ Department of Reproductive Health, \\ ${ }^{5}$ Department of Epidemiology and \\ Biostatistics, Institute of Public \\ Health, College of Medicine and \\ Health Sciences, University of Gondar. \\ Gondar, Ethiopia
}

Background: Viral load monitoring is used as an important biomarker for diagnosing treatment failure in patients with HIV infection/AIDS. Ethiopia has started targeted viral load monitoring. However, factors leading to virological failure are not well understood and studied. Thus, the aim of this study was to identify the determinants of virological failure among HIV-infected patients on highly active antiretroviral therapy at the University of Gondar Referral Hospital, Northwest Ethiopia.

Methods: A case-control study was conducted from May to June 2015. Cases were subjects who had already experienced virological failure; controls were those without virological failure. Data were extracted from 153 cases and 153 controls through chart review. A multivariate logistic regression analysis was carried out to identify factors associated with virological failure, and variables with a $p$-value $<0.05$ were considered statistically significant.

Results: In this study, higher odds of virological failure was observed among patients aged $<35$ years (adjusted odds ratio $[\mathrm{AOR}]=2.52,95 \% \mathrm{CI}: 1.33,4.77$ ), who had had CD4+ count $<200$ cells $/ \mathrm{mm}^{3}(\mathrm{AOR}=9.03,95 \% \mathrm{CI}: 4.40,18.50)$, showed poor adherence to antiretroviral therapy (ART) $(\mathrm{AOR}=15.80,95 \% \mathrm{CI}: 6.90,36.50)$, and had taken ART for longer durations of 25-47 months (AOR=3.00, 95\% CI: $1.10,8.40)$ and $\geq 48$ months (AOR=6.70, 95\% CI: 2.70, 16.60).

Conclusion: This study showed that patients aged $<35$ years and with recent low CD4 count, poor adherence to treatment, and longer exposure to ART were positively and significantly associated with virological treatment failure. Therefore, evidence-based intervention should be implemented to improve adherence to ART, which in turn helps to boost immunity (CD4) and suppresses viral replication and load. Moreover, attention should be given to younger patients who have had ART for longer periods.

Keywords: HIV, virological failure, highly active antiretroviral therapy, case-control study, Ethiopia

\section{Introduction}

HIV infection/AIDS has continued to be one of the top priorities of the health sector program of the Ethiopian government. ${ }^{1}$ Of the estimated 593,400 adults living with HIV, 298,512 were on treatment by the end of 2013. More than 45,200 people died due to AIDS in the same year. ${ }^{2}$

Highly active antiretroviral therapy (HAART), the lifesaving treatment for patients with HIV/AIDS, is an important component of the overall treatment plan. ${ }^{3}$ Since its
Correspondence: Destaw Fetene Teshome

Department of Epidemiology and Biostatistics, Institute of Public Health, College of Medicine and Health Sciences, University of Gondar, Gondar, Ethiopia

Tel +251918037193

Email destaw.fetene@gmail.com 
introduction, the impact of HIV infection has significantly decreased. ${ }^{4}$ The goal of the treatment is to suppress virus replication for as long as possible, restore and/or preserve immune function, improve quality of life, and reduce HIVrelated morbidity and mortality. ${ }^{5-7}$ But this has not always been apparent as many of the patients experience deterioration and develop treatment failure, which can be explained by virological, clinical, or immunological causes or all of these because they do not behave according to expectations. ${ }^{7}$

Virological failure, which is a more informative treatment failure, is a common problem that an HIV patient faces after starting treatment. ${ }^{8,9}$ Current guidelines recommend that once patients start treatment, virological failure should not exceed $10 \%{ }^{8,10}$ However, studies show that virological failure is much higher than expected, ${ }^{11-16}$ and viral replication continues to be a major challenge among patients living with HIV. ${ }^{11,17}$ Patients who experienced virological failure were found to have an increased risk of clinical progression to AIDS and mortality when compared with patients with complete virological response. ${ }^{17}$ Previous studies revealed that various factors were associated with virological failure. Accordingly, baseline CD4 count, ${ }^{15,17-19}$ younger age, ${ }^{12,14,20,21}$ longer time on HAART, ${ }^{15,16,20}$ poor adherence to treatment, ${ }^{20-23}$ and last lower CD4 count ${ }^{16,24}$ were associated with virological failure. On the other hand, extra baseline weight was negatively associated with virological failure.

Identifying and managing determinants of virological failure are of paramount importance to achieve a high treatment success rate and improve the quality of life. However, there is limited evidence on the determinants of virological failure among HIV-infected patients on HAART in Ethiopia and in the study area. Thus, this study aimed to identify the determinants of virological failure among HIV-infected patients on HAART at the University of Gondar Referral Hospital, Northwest Ethiopia.

\section{Methods}

\section{Study design and setting}

A hospital-based case-control study was conducted from May to June 2015 at the University of Gondar Referral Hospital. This hospital is a pioneer health facility located in Gondar district $748 \mathrm{~km}$ from Addis Ababa, the capital of Ethiopia, and provides health care services to $>5$ million residents of Northwest Ethiopia. The chronic HIV care center was launched in 2003 and free ART started in 2006. The service is provided in the Adult, Pediatric ART, and Prevention of Mother to Child Transmission (PMTCT) clinics. Ever since the launching of the care, about 12,470 HIV-infected clients were enrolled in the ART clinic. Out of these, 8,220 started ART and 5,138 are on HAART currently.

\section{Study participants and sample size determination}

All HIV-infected adults aged $\geq 15$ years and had been enrolled for ART with documented viral load results from 2010 to 2015 were included in the study. However, clients who had a follow-up of $<6$ months at the University of Gondar Referral Hospital were excluded.

All HIV-infected adults whose plasma viral load of $\geq 1,000$ copies $/ \mathrm{mL}$ in 2 consecutive viral load measurements in a 3-month interval after 6 months of starting a new ART regimen were defined as cases (virological failure) with adherent support, while study participants with a viral load level of $<1,000$ copies/mL were considered as controls. ${ }^{10}$

Sample size was determined using Epi Info ${ }^{\mathrm{TM}} 7$ StatCalc by taking the key predictor of virological failure (poor adherence) from a previous study. ${ }^{20}$ Therefore, the calculated sample size was 208 (104 cases and 104 controls). However, to improve the power of the study, all of the cases (153) and comparable controls (153) were included in the study. Controls were selected by using simple random sampling techniques.

\section{Data collection tools and procedure}

Data were extracted from patient charts using a pretested structured checklist. Accordingly, all charts containing detailed information about patients who were on HAART from 2010 to 2015 were reviewed. Six health professionals trained for 2 days collected the data. The principal investigator and the supervisor closely monitored the whole data collection process on a daily basis. Adherence to treatment was determined using the World Health Organization (WHO) definition in the follow-up chart. Thus, poor adherence to treatments is defined as patients taking $\leq 95 \%$ of the recommended regimens. ${ }^{7}$

\section{Statistical analysis}

Data were entered into Epi Info version 7 and analyzed using SPSS version 20. Descriptive statistics, including mean values and frequencies, were used to describe demographic, clinical, hematologic, and medication-related characteristics of patients. Bivariate analysis was carried out for all independent variables with an outcome variable. Using variables with a $p$-value of up to 0.2 , according to the bivariate analysis, a multivariate logistic regression analysis was carried out to identify the independent determinants of virological failure. 
The Hosmer-Lemeshow goodness-of-fit test for the model was also checked. Finally, variables that had significant associations with virological failure were identified based on the odds ratio (OR) with a $95 \% \mathrm{CI}$ and $p$-values $<0.05$.

\section{Ethical considerations}

Informed consent was waived by the Institutional Ethical Review Board of the University of Gondar and the Chief Clinical Officer of the University of Gondar Referral Hospital for this retrospective chart review, as all the data were de-identified. The confidentiality of information obtained from each study participant was guaranteed by omitting names or any personal identifiers. Moreover, the collected data were kept safe throughout the whole process of the research work to limit data accessibility to a third party.

\section{Results}

\section{Sociodemographic characteristics}

At baseline, the mean age of the cases and the controls was 32 years (SD: \pm 7 years) and 36 years (SD: \pm 10 years), respectively. Moreover, $80(53.6 \%)$ of cases and $79(51.6 \%)$ of the controls were females; $138(90.2 \%)$ of the cases and 132 $(86.3 \%)$ of the controls were Orthodox Christians. More than three-quarters $(75.8 \%$ and $79.7 \%)$ of the cases and controls, respectively, were urban dwellers (Table 1).

\section{Clinical-related characteristics}

Among the participants, 121 (79.1\%) cases and 111 (72.5\%) controls were classified as stages III and IV at baseline. Moreover, $33(21.6 \%)$ of the cases and 20 (13.1\%) of the controls developed tuberculosis (TB) before initiation of HAART, while one-quarter $(26.1 \%$ and $28.8 \%)$ of the cases and controls, respectively, acquired TB after enrollment in HAART (Table 2).

\section{Antiretroviral medication-related characteristics}

Almost half (49.7\%) of the cases and only 12 (7.8\%) of the controls had history of poor adherence to treatment. Nearly three-fourths (71.2\%) of the cases and half (49.1\%) of the controls were on HAART for $\geq 48$ months (Table 3 ).

\section{Hematologic profile of the study participants}

In this study, $135(88.2 \%)$ of the cases and 121 (78.9\%) of the controls had $<200$ cells $/ \mathrm{mm}^{3} \mathrm{CD} 4$ count at baseline, while $125(81.7 \%)$ of the cases and $74(48.4 \%)$ of the controls had CD4 count $<200$ cells $/ \mathrm{mm}^{3}$ at the previous visit.
Table I Sociodemographic characteristics of HIV-infected patients treated at the University of Gondar Referral Hospital: 2010-2015

\begin{tabular}{|c|c|c|}
\hline \multirow[t]{2}{*}{ Variables } & \multirow{2}{*}{$\begin{array}{l}\text { Cases } \\
\text { Frequency (\%) }\end{array}$} & \multirow{2}{*}{$\begin{array}{l}\text { Controls } \\
\text { Frequency (\%) }\end{array}$} \\
\hline & & \\
\hline \multicolumn{3}{|l|}{ Age, years } \\
\hline$<35$ & $99(64.7)$ & $73(47.7)$ \\
\hline$\geq 35$ & $54(35.3)$ & $80(52.3)$ \\
\hline \multicolumn{3}{|l|}{ Sex } \\
\hline Male & 71 (46.4) & $74(48.4)$ \\
\hline Female & $82(53.6)$ & $79(51.6)$ \\
\hline \multicolumn{3}{|l|}{ Residence } \\
\hline Urban & $116(75.8)$ & $122(79.7)$ \\
\hline Rural & $37(24.2)$ & $31(20.3)$ \\
\hline \multicolumn{3}{|l|}{ Marital status } \\
\hline Never married & $35(22.9)$ & $31(20.3)$ \\
\hline Married & $65(42.5)$ & $47(30.7)$ \\
\hline Others ${ }^{\mathrm{a}}$ & $53(34.6)$ & $75(49.0)$ \\
\hline \multicolumn{3}{|l|}{ Educational level } \\
\hline No schooling & $42(27.5)$ & $34(22.2)$ \\
\hline Primary school & $55(35.9)$ & $34(22.2)$ \\
\hline Secondary school & $56(36.6)$ & $85(55.6)$ \\
\hline \multicolumn{3}{|l|}{ Religion } \\
\hline Orthodox & $138(90.2)$ & $132(86.3)$ \\
\hline Others ${ }^{\mathrm{b}}$ & $15(9.8)$ & $21(13.7)$ \\
\hline \multicolumn{3}{|l|}{ Occupation } \\
\hline Not employed & $48(31.4)$ & $50(32.7)$ \\
\hline Government employed & $24(15.7)$ & $42(27.5)$ \\
\hline Self-employed & $41(26.8)$ & $31(20.2)$ \\
\hline Daily laborer & $40(26.1)$ & $30(19.6)$ \\
\hline
\end{tabular}

Notes: aDivorced, separated, or widowed; bMuslim or Protestant.

\section{Factors associated with HIV virological failure}

The bivariate logistic regression analysis showed that age, educational status, occupation, ART medication adherence, TB coinfection, baseline WHO clinical stage, current body mass index (BMI), first-line ART, duration on ART, baseline and recent CD4 count, current WBC count, and hemoglobin level were associated with antiretroviral virological failure.

After adjustment for possible effects of confounding variables, patients aged $<35$ years, with recent CD4 count $<200$ cells $/ \mathrm{mm}^{3}$, poor adherence to ART, and longer duration of ART enrollment were significantly associated with virological failure.

The likelihood of developing virological failure for patients aged $<35$ years was 2.5 times (adjusted OR [AOR] $=2.52,95 \% \mathrm{CI}: 1.33,4.77)$ as likely as compared with their older counterparts. Patients who had had a recent CD4 count of $<200$ cells $/ \mathrm{mm}^{3}$ were 9 times $(\mathrm{AOR}=9.03,95 \% \mathrm{CI}: 4.40$, 18.50) as likely to have virological failure as those with higher CD4 counts. Patients who were poorly adherent to their ART were 16 times $(\mathrm{AOR}=15.80,95 \% \mathrm{CI}: 6.90,36.50)$ 
Table 2 Behavioral and clinical-related information among HIV-positive adults who have had follow-up at the University of Gondar Referral Hospital: 2010-2015

\begin{tabular}{lll}
\hline Variables & Cases & Controls \\
\cline { 2 - 3 } & Frequency (\%) & Frequency (\%) \\
\hline Baseline BMI, kg/m² & & \\
$<16.5$ & $22(14.4)$ & $19(11.8)$ \\
$16.5-18.49$ & $48(31.4)$ & $49(32.2)$ \\
$\geq 18.5$ & $83(54.2)$ & $85(55.9)$ \\
Current BMI, kg/m & & \\
$<16.50$ & $28(18.3)$ & $17(10.5)$ \\
I6.50-I8.49 & $27(17.6)$ & $28(18.4)$ \\
$\geq 18.50$ & $98(64.1)$ & $108(71.1)$ \\
WHO clinical stage & & \\
Stages I and II & $32(20.9)$ & $42(27.5)$ \\
Stages III and IV & $121(79.1)$ & $111(72.5)$ \\
History of TB & & \\
Before ART & $33(21.6)$ & $20(13.1)$ \\
After ART & $40(26.1)$ & $44(28.8)$ \\
Duration with HIV, months & & \\
$6-24$ & $9(5.9)$ & $28(18.3)$ \\
$24-47$ & $30(19.6)$ & $46(30.1)$ \\
$\geq 48$ & $114(74.5)$ & $79(51.6)$ \\
History of substance use & & $35(22.9)$ \\
Yes & $27(17.6)$ & $118(77.1)$ \\
No & $126(82.4)$ & \\
\hline Abbrevition & &
\end{tabular}

Abbreviations: ART, antiretroviral therapy; BMI, body mass index; TB, tuberculosis.

as likely to have virological failure as compared to those who were adherent to their treatment. Patients who took ART for 24-47 months and for $>48$ months were 3 times ( $\mathrm{AOR}=3.00$, 95\% CI: $1.10,8.40)$ and 7 times (AOR=6.7, 95\% CI: 2.7, $16.60)$, respectively, as likely to have virological failure as those who took the treatment for 6-24 months (Table 4).

\section{Discussion}

This study investigated the determinants of ART virological failure and revealed that patients aged $<35$ years, with recent low CD4 count ( $<200$ cells $/ \mathrm{mm}^{3}$ ), poor adherence to treatment, and longer duration on HAART enrollment were found to have increased odds of virological failure.

In this study, patients aged $<35$ years were associated with virological failure. Similar findings were reported from Nyanza region, Kenya, ${ }^{12}$ Cameroon, ${ }^{14}$ Mozambique, ${ }^{20}$ and France, ${ }^{21}$ where the likelihood of developing ART virological failure was higher among younger patients. This might be due to differences in lifestyles, as most of the younger adults commonly suffered from less healthy personality traits and were more vulnerable to substance abuse. Moreover, they had less emotional stability to cope with the social stigma, discrimination, and the adverse consequences of the disease itself. This suggests that depression, anxiety, and unhealthy
Table 3 Antiretroviral medication-related information among HIV-positive adults who have had follow-up at the University of Gondar Referral Hospital: 2010-2015

\begin{tabular}{lll}
\hline Variables & Cases & Controls \\
\cline { 2 - 3 } & Frequency (\%) & Frequency (\%) \\
\hline Adherence to treatment & & \\
Good & $77(50.3)$ & $141(92.2)$ \\
Poor & $76(49.7)$ & $12(7.8)$ \\
CPT use & & \\
Yes & $142(92.8)$ & $139(90.8)$ \\
No & II (7.2) & $14(9.2)$ \\
First-line ART regimen & & \\
AZT based & $48(31.4)$ & $78(51.0)$ \\
TDF based & $40(26.1)$ & $37(24.2)$ \\
D4T based & $65(42.5)$ & $38(24.8)$ \\
Change of ARV regimen or individual drugs & \\
Yes & $73(47.7)$ & $72(47.1)$ \\
No & $80(52.3)$ & $81(52.9)$ \\
ART regimen at the time of VL test & \\
TDF based & $67(43.8)$ & $63(41.2)$ \\
AZT based & $86(56.2)$ & $90(58.8)$ \\
ART duration, months & & \\
6-24 & I3 (8.5) & $38(24.8)$ \\
24-47 & $31(20.3)$ & $40(26.1)$ \\
$\geq 48$ & $109(71.2)$ & $75(49.1)$ \\
\hline A6b
\end{tabular}

Abbreviations: ART, antiretroviral therapy; ARV, antiretroviral; AZT, azidothymidine; BMI, body mass index; CPT, cotrimoxazole preventive therapy; D4T, stavudine; TB, tuberculosis; TDF, tenofovir disoproxil fumarate; VL, viral load.

behaviors could negatively affect dietary intake and treatment outcomes of clients. ${ }^{25}$

Patients with a recent low CD4 count were 9 times as likely to develop virological failure as those with higher CD4 count $\left(>200\right.$ cells $/ \mathrm{mm}^{3}$ ). The finding was consistent with those of studies conducted in Swaziland ${ }^{16}$ and northwestern Uganda. ${ }^{24}$ It is well known that CD4 count has an inverse relationship with viral replication and load. As patients' immune status becomes compromised, the rate of viral replication increases compared to their immune-competent counterparts. Furthermore, clients with compromised immunity are more vulnerable to different opportunistic infections that sustain the vicious cycle of immunity and viral replication. ${ }^{6}$

Adherence to ART was also an important determinant of virological failure. Patients with poor medication adherence were 16 times as likely to develop virological failure as patients with good adherence. The finding was consistent with those of studies conducted in Mozambique, ${ }^{20}$ France, ${ }^{21}$ China, ${ }^{22}$ and Guangxi, China, ${ }^{23}$ where poor medication adherence was the main risk factor for virological failure. It is evident that individuals missing 3 doses of ART per month are associated with an increased risk of drug resistance and reduced immunity. ${ }^{6}$ This results in the loss of the opportunity to suppress viral replication and leads to virological failure. ${ }^{7}$ 
Table 4 Determinants of ART virological failure among HIV-positive adults who had follow-up at the University of Gondar Referral Hospital: 2010-2015

\begin{tabular}{|c|c|c|c|c|}
\hline \multirow[t]{2}{*}{ Variables } & \multicolumn{2}{|c|}{ Virological failure } & \multirow[t]{2}{*}{ COR $(95 \% \mathrm{Cl})$} & \multirow[t]{2}{*}{ AOR (95\% Cl) } \\
\hline & Cases, n (\%) & Controls, n (\%) & & \\
\hline \multicolumn{5}{|l|}{ Age, years } \\
\hline$<35$ & $99(64.7)$ & $73(47.7$ & $2.00(1.27,3.18)^{*}$ & $2.52(1.33,4.77)^{*}$ \\
\hline$\geq 35$ & $54(35.3)$ & $80(52.3)$ & I & - \\
\hline \multicolumn{5}{|l|}{ Educational status } \\
\hline No schooling & $42(27.5)$ & $34(22.2)$ & I & - \\
\hline Primary & $55(35.9)$ & $34(22.2)$ & $1.88(1.07,3.23)^{*}$ & - \\
\hline Secondary & $56(36.6)$ & $85(55.6)$ & $2.56(1.42,4.23)^{*}$ & - \\
\hline \multicolumn{5}{|l|}{ Occupation } \\
\hline Unemployed & $48(31.4)$ & $50(32.7)$ & I & - \\
\hline Employed & $24(15.7)$ & $42(27.5)$ & $0.59(0.31,1.13)$ & - \\
\hline Self-employed & $41(26.8)$ & $31(20.3)$ & $1.38(0.75,2.54)$ & - \\
\hline Daily laborer & $40(26.1)$ & $30(19.6)$ & $1.39(0.75,2.57)$ & - \\
\hline \multicolumn{5}{|l|}{ WHO clinical stage } \\
\hline Stages I and II & $32(20.9)$ & $42(27.5)$ & I & - \\
\hline Stages III and IV & I2I (79.I) & III (72.5) & I. $43(0.84,2.42)$ & - \\
\hline \multicolumn{5}{|l|}{ Adherence } \\
\hline Good & $77(50.3)$ & $|4|(92.2)$ & 1 & - \\
\hline Poor & $76(49.7)$ & $12(7.8)$ & $12.4(6.26,24.9)^{*}$ & I5.8 $(6.90,36.50)^{*}$ \\
\hline \multicolumn{5}{|l|}{ History of TB } \\
\hline No TB & $80(52.3)$ & $89(58.2)$ & I & - \\
\hline Before ART & $33(21.6)$ & $20(13.1)$ & $1.84(0.976,3.45)$ & - \\
\hline After ART & $40(26.1)$ & $44(28.7)$ & $1.01(0.60,1.71)$ & - \\
\hline \multicolumn{5}{|c|}{ First-line ART regimen } \\
\hline D4T based & $65(42.5)$ & $38(24.8)$ & $0.36(0.21,0.62)^{*}$ & - \\
\hline AZT based & $48(31.4)$ & $78(51.0)$ & $0.63(0.34,1.14)$ & - \\
\hline TDF based & $40(26.1)$ & $37(24.2)$ & 1 & - \\
\hline \multicolumn{5}{|c|}{ Duration on ART, months } \\
\hline $6-24$ & $13(8.5)$ & $38(24.8)$ & 1 & 1 \\
\hline $24-47$ & $31(20.3)$ & $40(26.1)$ & $2.26(1.03,4.97)^{*}$ & $3.00(1.10,8.40)^{*}$ \\
\hline$\geq 48$ & $109(7 \mid .2)$ & $75(49.1)$ & $4.25(2.12,8.52)^{*}$ & $6.7(2.7,16.60)^{*}$ \\
\hline \multicolumn{5}{|l|}{ Current BMI, kg/m² } \\
\hline$<16.5$ & $28(18.3)$ & $17(10.5)$ & $1.92(0.98,3.78)$ & - \\
\hline $16.5-18.49$ & $27(17.6)$ & $28(18.4)$ & $1.06(0.58,1.97)$ & - \\
\hline$\geq 18.5$ & $98(64.1)$ & $108(7 \mid . I)$ & I & - \\
\hline \multicolumn{5}{|c|}{ Current WBC count, cells $/ \mathrm{mm}^{3}$} \\
\hline$<4,000$ & $59(37.8)$ & $36(23.8)$ & $1.94(1.18,3.20)^{*}$ & - \\
\hline$\geq 4,000$ & $94(62.2)$ & 117 (76.2) & I & - \\
\hline \multicolumn{5}{|c|}{ Current hemoglobin level, g/dL } \\
\hline$<12$ & $37(24.2)$ & $24(15.9)$ & $1.68(0.95,2.99)$ & - \\
\hline$\geq 12$ & $116(75.8)$ & $129(84.1)$ & I & - \\
\hline \multicolumn{5}{|c|}{ Baseline CD4 count, cells $/ \mathrm{mm}^{3}$} \\
\hline$<200$ & $135(88.2)$ & I2I (79.I) & $2.00(1.07,3.75)^{*}$ & - \\
\hline$\geq 200$ & $18(11.8)$ & $32(20.9)$ & I & - \\
\hline \multicolumn{5}{|c|}{ Current CD4 count, cells $/ \mathrm{mm}^{3}$} \\
\hline$<200$ & $125(81.7)$ & $74(48.4)$ & $4.77(2.84,8.00)^{*}$ & $9.03(4.40,18.50)^{*}$ \\
\hline$\geq 200$ & $28(18.3)$ & $79(51.6)$ & I & 1 \\
\hline
\end{tabular}

Notes: *Significant at a $p$-value of $<0.05$; Hosmer-Lemeshow test $=0.702$.

Abbreviations: AOR, adjusted odds ratio; ART, antiretroviral therapy; AZT, azidothymidine; BMI, body mass index; COR, crude odds ratio; D4T, stavudine; TB, tuberculosis; TDF, tenofovir disoproxil fumarate.

Duration of ART was a significant factor associated with virological failure. This study showed that the likelihood of virological failure was 3 and 7 times more among patients who took ART for $\sim 24-47$ months and $\geq 48$ months, respectively, compared to patients who took the treatment for 6-24 months. This finding is supported by studies conducted in Gabon, ${ }^{15}$ Swaziland, ${ }^{16}$ and Mozambique. ${ }^{20}$ The possible reason might be that as the duration of ART increased, the 
likelihood of developing poor adherence and drug interruption, as well as drug side effects, also increased. ${ }^{6}$ All these factors might have led to virological failure.

\section{Conclusion}

This study showed that age $<35$ years, low CD4 count, poor adherence to treatment, and higher duration of taking ART were positively and significantly associated with virological failure. Therefore, efforts should be strengthened to improve adherence to ART, which helps to boost immunity and suppress viral replication and load. Moreover, more attention should be given to younger patients who have taken ART for a prolonged duration.

\section{Acknowledgments}

We are indebted to the University of Gondar for permission to conduct the study. Our gratitude also goes to the data collectors and supervisors who participated in the study.

\section{Author contributions}

All authors contributed toward data analysis, drafting and critically revising the paper and agree to be accountable for all aspects of the work.

\section{Disclosure}

The authors report no conflicts of interest in this work.

\section{References}

1. HIV/AIDS in Ethiopia: An Epidemiological Synthesis. Addis Ababa, Ethiopia: Federal HIV/AIDS Prevention and Control Office; 2014.

2. Country Progress Report on The HIV Response. Addis Ababa, Ethiopia: Federal Democratic Republic of Ethiopia; 2014.

3. UNHCR. Clinical Guidelines for Antiretroviral Therapy Management for Displaced Populations Southern Africa. Geneva, Switzerland: Southern African HIV Clinicians Society; 2007.

4. HIV/AIDS Progress in 2014. UNECA Compound. Addis Abeba, Ethiopia: World Health Organization Ethiopia Country Office; 2015.

5. Churchill D, Waters L, Ahmed N, et al. British HIV Association guidelines for the treatment of HIV-1-positive adults with antiretroviral therapy 2015. Br HIV Assoc. 2015;17(S4):s2-s104.

6. AIDSinfo. Guidelines for the Use of Antiretroviral Agents in HIV-1Infected Adults and Adolescents. 2016.

7. NACO. ART Guidelines for HIV-Infected Adults and Adolescents. Ministry of Health and Family Welfare Government of India; 2013.

8. WHO. Consolidated Guidelines on the Use of Antiretroviral Drugs for Treating and Preventing HIV Infection. Recommendations for a Public Health Approach; 2016.
9. WHO. To the 2013 Consolidated Guidelines on the Use of Antiretroviral Drugs for Treating and Preventing HIV Infection. Geneva, Switzerland: Recommendations for a Public Health Approach; 2014.

10. WHO. Guideline on When to Start Antiretroviral Therapy and on PreExposure Prophylaxis for HIV. 2015.

11. Leng X, Liang S, MaY, et al. HIV virological failure and drug resistance among injecting drug users receiving first-line ART in China. BMJ Open. 2014;4(10):e005886.

12. Sang RKA, Miruka FO. Factors associated with virologic failure amongst adults on antiretroviral therapy in Nyanza Region, Kenya. IOSR J Dent Med Sci. 2016;15(7):108-121.

13. Vidal JE, Song ATW, Matos ML, et al. High rate of virologic suppression with darunavir/ritonavir plus optimized background therapy among highly antiretroviral-experienced HIV-infected patients: results of a prospective cohort study in São Paulo, Brazil. Braz J Infect Dis. 2013;17(1): $41-47$.

14. Meriki HD, Tufon KA, Afegenwi MH, et al. Immuno-haematologic and virologic responses and predictors of virologic failure in HIV-1 infected adults on first-line antiretroviral therapy in Cameroon. Infect Dis Poverty. 2014;3:5.

15. Liégeois F, Vella C, Eymard-Duvernay S, et al. Virological failure rates and HIV-1 drug resistance patterns in patients on first-line antiretroviral treatment in semirural and rural Gabon. $J$ Int AIDS Soc. 2012;15(2):17985.

16. Jobanputra K, Parker LA, Azih C, et al. Factors associated with virological failure and suppression after enhanced adherence counselling, in children, adolescents and adults on antiretroviral therapy for HIV in Swaziland. PLoS One. 2015;10(2):e0116144.

17. Kitchen CM, Kitchen SG, Dubin JA, Gottlieb MS. Initial virological and immunologic response to highly active antiretroviral therapy predicts long-term clinical outcome. Clin Infect Dis. 2001;33(4):466-472.

18. Deeks SG. Determinants of virological response to antiretroviral therapy: implications for long-term strategies. Clin Infect Dis. 2000;30(2):S177-S184.

19. Grabar S, Pradier C, Corfec EL, et al. Factors associated with clinical and virological failure in patients receiving a triple therapy including a protease inhibitor. AIDS. 2000;14(2):141-149.

20. Rupérez M, Pou C, Maculuve S, et al. Determinants of virological failure and antiretroviral drug resistance in Mozambique. J Antimicrob Chemother. 2015;70(9):2639-2647.

21. Parienti JJ, Massari VR, Descamps D, et al. Predictors of virologic failure and resistance in HIV-infected patients treated with nevirapine- or efavirenz-based antiretroviral therapy. Clin Infect Dis. 2004;38(9):1311-1316.

22. Zuo Z, Liang S, Sun X, et al. Drug resistance and virological failure among HIV-infected patients after a decade of antiretroviral treatment expansion in eight provinces of China. PLoS One. 2016;11(12):e0166661.

23. Liang S, Shen Z, Yan J, et al. Low virologic failure and drug resistance among HIV-infected patients receiving hospital-based ART while care and outreach through community in Guangxi, China. Front Public Health. 2015;3:244.

24. Izudi J, Alioni S, Kerukadho E, Ndungutse D. Virological failure reduced with HIV serostatus disclosure, extra baseline weight and rising CD4 cells among HIV-positive adults in Northwestern Uganda. BMC Infect Dis. 2016;16(1):614.

25. Rabkin JG. HIV and depression: 2008 review and update. Behav Aspects HIV Manag. 2008;5(4):163-171. 
HIV/AIDS - Research and Palliative Care

\section{Publish your work in this journal}

HIV/AIDS - Research and Palliative Care is an international, peerreviewed open access journal focusing on advances in research in HIV its clinical progression and management options including antiviral treatment, palliative care and public healthcare policies to control viral spread. The journal is included in PubMed. The manuscript man-
Dovepress

agement system is completely online and includes a very quick and fair peer-review system, which is all easy to use. Visit http://www.dovepress. com/testimonials.php to read real quotes from published authors.

Submit your manuscript here: https://www.dovepress.com/hivaids---research-and-palliative-care-journal 